\title{
Vascular lesion of the lip treated with a diode laser: A case report.
}

\author{
Cinzia Casu ${ }^{1 *}$, Riccardo Botta ${ }^{2}$, Carla Mannu ${ }^{3}$ \\ ${ }^{1}$ Private Dental Practice, Cagliari, Italy \\ ${ }^{2}$ Department of Dentistry, IRCSS San Raffaele Hospital, Vita Salute, Dental School, University of Milano, Milano, \\ Italy \\ ${ }^{3}$ Diabetology, San Michele Hospital, Cagliari, Italy
}

\begin{abstract}
The classification of vascular lesions of the oral cavity is complex. To simplify, these lesions can be divided into two large groups: neoplasms (mostly benign) and vascular malformations. Laser treatment of oral vascular lesions seems to be an excellent device, and different wavelengths have been reported in the literature. The purpose of this work is to document a case of vascular lesion of the lip, developed in a few weeks in an adult patient successfully treated with a minimally invasive technique with the use of diode laser $810 \mathrm{~nm}$. A young adult female patient was referred for a labial exophytic lesion that continued to grow despite previous topical therapies prescribed by dermatologists. The first dermatologist diagnosed herpetic manifestation and the second diagnosed labial granuloma. The patient has been subjected to ultrasound examination, which confirmed the suspected diagnosis of the benign vascular injury. The patient underwent 3 photocoagulation sessions performed with $810 \mathrm{~nm}$ diode laser and after 2 months the lesion completely healed without scarring and without alteration of sensitivity. Lip diseases are often treated dermatologists, although the labial mucosa belongs to the oral cavity. Through the use of a safety device, this type of injury can be managed within the dental office, and so an opportunity for dental practice. The diode laser can be considered safe and effective in the treatment of vascular lesions of the lip.
\end{abstract}

Keywords: Lip lesions, Vascular oral lesion, 808 nm Diode laser, Vascular lip lesions.

\section{Introduction}

The classification of vascular lesions of the oral cavity is complex and has recently changed. To simplify, these lesions can be divided into two large groups: neoplasms (mostly benign) and vascular malformations [1]. Hemangioma is a benign vascular lesion of the oral cavity and may also occur in the labial border [2]. Vascular malformations include a series of pathologies characterized by the alteration of vascular structures proliferation. These changes can be congenital or acquired, usually, the latter appear after a traumatic event or surgery [3]. They affect men more frequently and rarely affect the labial tissue. Diagnosis of these lesions is essentially clinical that are accompanied by instrumental investigations such as the eco color doppler. Although the use of a needle aspiration can help the clinician for an immediate diagnosis, avoid biopsies and subsequent analysis from microscopic histological images [4]. The biopsy is useful to other kinds of screening but it could cause copious bleeding [5]. Often it is possible to appreciate a pulsation of the blood vessels involved [3]. Another vascular entity affecting the lip is the persistent caliber artery. It's an artery that infiltrates even in submucous tissues and that doesn't branch and isn't reduced in size, causing the formation of labial lesions, which sometimes can undergo ulceration and therefore hemorrhage [6]. Also, in this case, clinical and ultrasound examination can lead us to the diagnosis without biopsies. Benign variants of vascular lesions that may affect the lip have been described in the literature, although very rare as angioleiomyoma and angiomyolipoma [7-9].

The treatment of this type of lesions is often required only for aesthetic reasons because are asymptomatic, especially if smaller than $1 \mathrm{~cm}$ and with a little risk of traumatization. Among the treatments proposed in the scientific literature, there are sclerotherapy or injections with sodium tetradecyl sulfate $[10,11]$, cryotherapy with liquid nitrogen [12], photocoagulation therapy with neodymium laser $(1064 \mathrm{~nm})$ and a high-intensity diode laser [13-15].

The purpose of this work is to document a case of vascular lesion of the lip, developed in a few weeks in an adult patient, successfully treated with a minimally invasive technique with the use of $808 \mathrm{~nm}$ diode laser.

\section{Clinical Case}

29 years old female patient went to our private practice for a labial exophytic lesion. Anamnesis reported good general health condition and capillary fragility. She referred to us for some weeks, the lesion continued to grow despite previous topical therapies prescribed by dermatologists. A specialist diagnosed herpetic manifestation and therefore patient was treated with topical antiviral therapy without any benefit. A second dermatologist diagnosed labial granuloma and prescribed topical antibiotic therapy, while the lesion continued to grow. Clinical appearance was a red lesion, about $1.5 \mathrm{~cm}$ in diameter, which was lightened to pressure (Figure 1). It was decided to subject the patient to an ultrasound examination, which confirmed the suspected diagnosis of the benign vascular injury. Given the site and the protrusion of the lesion, so the traumatic risk with possible hemorrhage, it was decided to act conservatively. The patient underwent 3 photocoagulation sessions performed with $810 \mathrm{~nm}$ diode lasers, 2 weeks after each session. The 
fiber used was 320 microns, activated, and was brought to about $10 \mathrm{~mm}$ from the affected mucosa with circular movements. Two cycles of 60 seconds, 2.5 watts of power were performed; 2 cycles from 60 seconds, 3 watts and finally another 2 cycles with a power of 3.5 watts (Figure 2). From the following day, the lesion became dark and smaller (Figure 3 ). After 2 weeks, the lesion was significantly reduced (Figure 4). In the following two sessions, only 2 cycles from 60 seconds with 2.5 watts and 2 cycles with 3 watts of power had been performed (Figures 5 and $6)$. After 2 months the lesion completely healed without scarring and without alteration of the sensitivity (Figure 7).

\section{Discussion}

In addition to the aforementioned pathologies, this lesion could be placed in differential diagnosis with pyogenic granuloma,

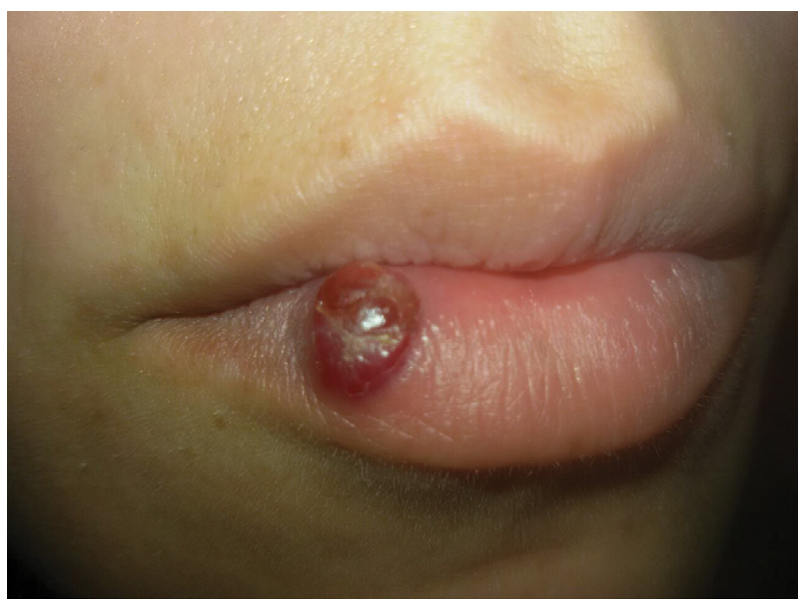

Figure 1. Initial situation.

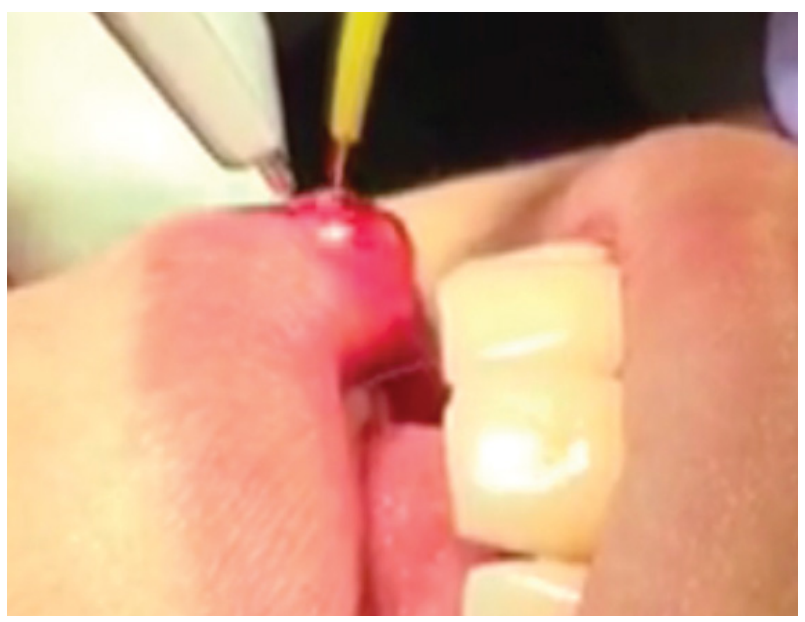

Figure 2. Laser therapy session $808 \mathrm{~nm}$ with watts 3.5-2.5.

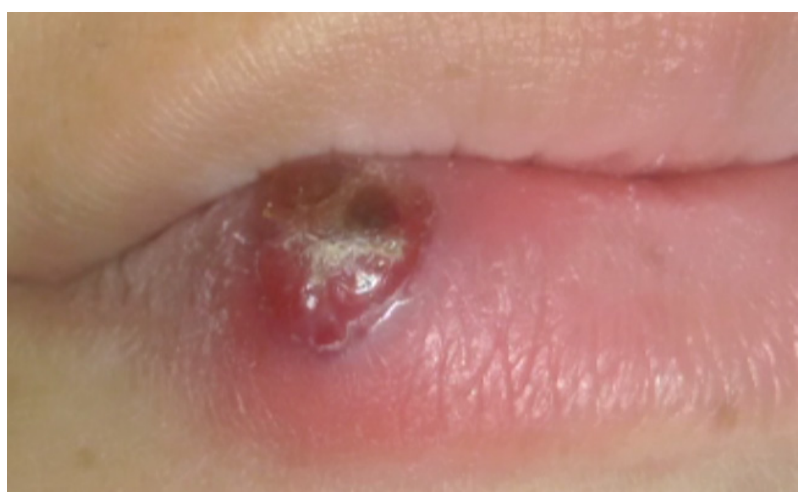

Figure 3. Lesion at 1 day after the first session.

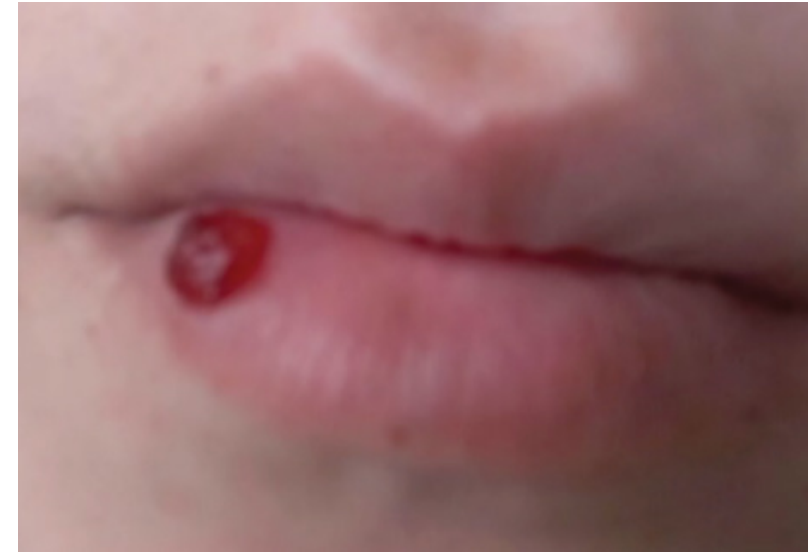

Figure 4. Lesion at $2^{\text {nd }}$ week before the second session.

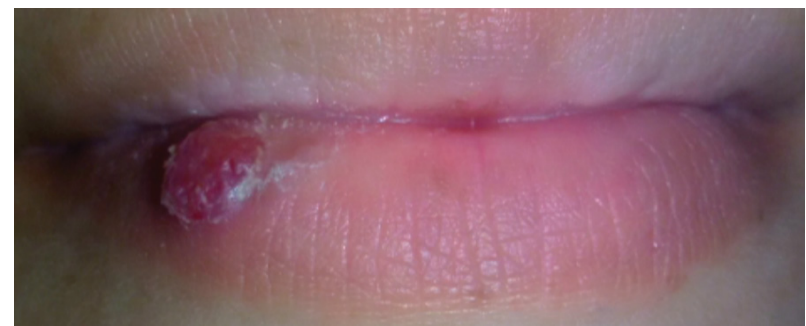

Figure 5. Lesion after the second session laser.

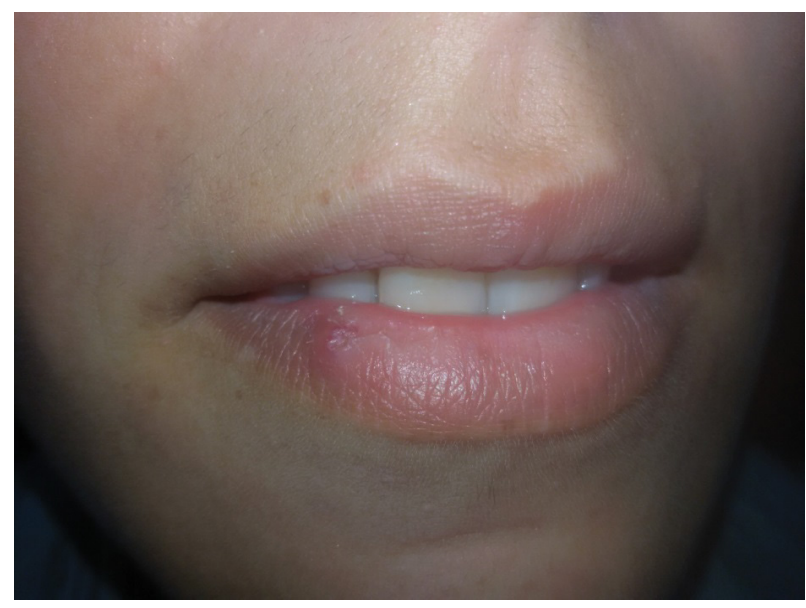

Figure 6. Injury in clear healing.

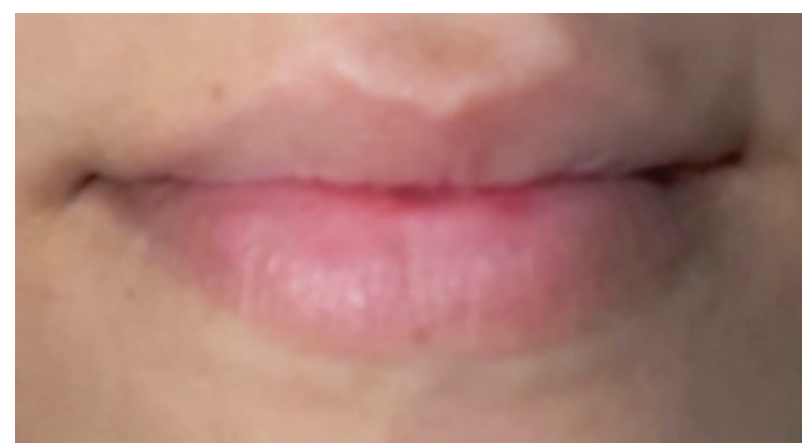

Figure 7. Final situation, complete healing.

angiofibroma, cavernous hemangioma, epithelioid hemangioma [1619]. The pyogenic granuloma is an entity that affects the skin or the oral cavity characterized by the formation of erythematous papules, however rare in the lip [16]. Angiofibroma is a benign vascular lesion that rarely developed in the lip, often in the nasal mucosa [17]. Cavernous hemangioma predominantly involves children, and 
when an abnormal dilation of the blood vessels occurs, it is called cavernous [16]. Epithelioid hemangioma is extremely rare in unknown etiology and differs from other vascular lesions due to the presence of endothelial cells intermingled with epithelial cells [19]. In this case, the ultrasound of the labial tissue was sufficient to elucidate the benign nature of the vascular lesion and it was decided to treat it as conservatively as possible. The use of sclerosing agents has been documented in literature, although it may be related to the occurrence of minimal side effects [11], while the use of cryotherapy has shown excellent results [12], but in a recent study was associated with the presence of serious injuries to the treated organs and pain, even if not in oral mucosa [20].

\section{Conclusion}

The laser treatment of oral vascular lesions seems to be an excellent device, and different wavelengths have been reported in the literature. In a recent study, the Neodymium laser was used to successfully treat 93 patients with labial lesions, without any collateral damage, with a maximum of 2 sessions [14]. Bacci et al. performed laser therapy sessions on 59 patients with labial vascular pathologies, performing only 6 cases of additional treatments with negligible side effects [13]. The use of the 810 $\mathrm{nm}$ diode laser with powers varying between 2.5 and 3.5 watts for labial vascular lesions over one centimeter has not yet been documented in the literature. Lip diseases are often treated by the dermatologist, although the labial mucosa belongs to the oral cavity. Through the use of a safety device, this type of injury can be managed within the dental office, offering an opportunity for dental practice. The diode laser can be considered safe and effective in the treatment of vascular lesions of the lip.

\section{References}

1. George A, Mani V, Noufal A. Update on the classification of hemangioma. J Oral Maxillofac Pathol. 2014;18(1):117.

2. Pandhare MN, Jyoti DB, Mandale MS, et al. Acquired arteriovenous malformation of lip occurring as an occupational hazard: A case report with review of literature. J Oral Maxillofac Pathol. 2018;22(2):287.

3. Murakami K, Yamamoto K, Sugiura T, et al. Spindle cell hemangioma in the mucosa of the upper lip: A case report and review of the literature. Case Rep Dent. 2018:7.

4. Yan J, Thomson JK, Wu X, et al. Novel methods of automated quantification of gap junction distribution and interstitial collagen quantity from animal and human atrial tissue sections. PloS One. 2014;9(8):104357.

5. Ridaura-Sanz C, Durán-McKinster C, Ruiz-Maldonado R. Usefulness of the skin biopsy as a tool in the diagnosis of silvery hair syndrome. Pediatr Dermatol. 2018;35(6):780-83.

6. Thanthoni M, Rajeev P, Sathasivasubramanian S. Caliber- persistent labial artery: A report of a rarely recognized lip swelling. J Clin Imaging Sci. 2018;8:41.

7. Matiakis A, Karakostas P, PavlouAM, et al. Angioleiomyoma of the oral cavity: a case report and brief review of the literature. J Korean Assoc Oral Maxillofac Surg. 2018;44(3):136-39.

8. Silva AA, Carlos R, Contreras E, et al. Angiomyolipoma of the upper lip: Case report and review of the literature. Med Oral Patol Oral Cir Bucal. 2007;12(2):101-04.

9. Sabharwal A, Aguirre A, Zahid TM, et al. Acquired tufted angioma of upper lip: Case report and review of the literature. Head Neck Pathol. 2013;7(3):291-94.

10. Choi BE, Kim Y, Leem DH, et al. Utility of sodium tetradecyl sulfate sclerotherapy from benign oral vascular lesion. Maxillofac Plastic Reconst Surg. 2016;38(1):44.

11. Mishra M, Singh G, Gaur A, et al. Role of sclerotherapy in management of vascular malformation in the maxillofacial region: Our experience. Natl J Maxillofac Surg. 2017;8(1):64.

12. Nogueira PT, Remigio MM, Queiroz AM, et al. Cryosurgery as an option for the treatment of vascular Lesions of the oral cavity. Case Rep Otolaryngol. 2017.

13. Bacci C, Sacchetto L, Zanette G, et al. Diode laser to treat small oral vascular malformations: A prospective case series study. Lasers Surg Med. 2018;50(2):111-16.

14. Cadavid AM, de Campos WG, Aranha AC, et al. Efficacy of photocoagulation of vascular malformations in the oral mucosa using Nd: YAG Laser. J Craniofac Surg. 2018;29(6):614-17.

15. Azevedo LH, Migliari D. Management of an extensive vascular lesion on the lip by photocoagulation with highintensity diode laser. Open Dent J. 2017;11:242.

16. Demirkan S. Management of a recurrent pyogenic granuloma of the inferior lip with pulsed dye laser: A case report. J Am Coll Clin Wound Spec. 2016;8(1-3):39-41.

17. Goud S, Swapna T, Bindu H, et al. Extra nasopharyngeal angiofibroma simulating a mucocele: A new location for the rare entity. J Clinl Diag Res. 2017;11(1):28.

18. Avila ÉD, Molon RS, Conte Neto N, et al. Lip cavernous hemangioma in a young child. Braz Dent J. 2010;21(4):370-74.

19. Aggarwal A, Keluskar V. Epithelioid hemangioma (angiolymphoid hyperplasia with eosinophilia) in the oral mucosa. Ind J Dent Res. 2012;23(2):271.

20. Power NE, Silberstein JL, Tarin T, et al. Endoscopic spray cryotherapy for genitourinary malignancies: Safety and efficacy in a porcine model. Ther Adv Urol. 2013;5(3):135-41. 